\title{
Tracking overweight and obesity in Japanese children ; a six years longitudinal study
}

\author{
Takuro Nakano', Masako Sei', Ashraf A. Ewis', Hokuma Munakata', \\ Chiemi Onishi', and Yutaka Nakahori' \\ 1. Department of Human Genetics and Public Health, Institute of Health Biosciences, the University \\ of Tokushima Graduate School, Tokushima, Japan
}

\begin{abstract}
Childhood overweight/obesity is growing steeply, globally. It is usually regarded as a risk factor for severe obesity over life-time course. Here, we investigated temporal course of overweight/obesity development in Japanese school children. A six-year longitudinal study was performed on 16,245 Japanese primary school children $(8,427$ boys and 7,818 girls) comprising three cohorts of $1^{\text {st }} \sim 3^{\text {rd }}$ grade. A baseline survey was conducted at 2001, followed by annual baseline studies from 2002 2007 to determine the prevalence and track overweight/obesity. Our results showed that the prevalence of overweight was 15 23\% in boys and 15 18\% in girls, however, for obesity it ranged between $4 \sim 7 \%$ in boys ; and 2 4\% in girls. As regards for tracking status, 60 80\% of overweight and 35 70\% of obese Japanese primary school boys track into overweight or obese junior high school adolescents. However, these percentages are lower among primary school girls, where only 50 70\% overweight and 30 60\% obese primary school girls track into overweight and obese adolescents, respectively. We conclude that Japanese boys are fatter than girls ; and $\sim 80 \%$ of overweight/obese Japanese primary school children track into junior high school overweight/obese adolescents. J. Med. Invest. 57 : 114-123, February, 2010
\end{abstract}

Keywords : childhood obesity, tracking, adolescent health, longitudinal studies, Japanese school children

\section{INTRODUCTION}

The prevalence of overweight and obesity has increased globally, forming a serious problem among children and adults ; and they are becoming one of the major public health issues in the developed countries including Japan (1-6). Childhood overweight and obesity comprise a risk factor for adulthood obesity ; and strong associations of overweight and/or obesity with cardiovascular

Received for publication November 13, 2009 ; accepted December 16, 2009.

Address correspondence and reprint requests to Masako Sei, Department of Human Genetics and Public Health, Institute of Health Biosciences, the University of Tokushima Graduate School, Kuramoto-cho, Tokushima 770-8503 Japan and Fax : +81-88-633-7453. diseases and metabolic syndrome in adolescence has been established (7-10).

Measuring the body mass index $\left(\mathrm{BMI}, \mathrm{kg} / \mathrm{m}^{2}\right)$ is a simple and acceptable screening anthropometric measurement for detecting overweight and obesity in children and adolescents (11). However, during childhood the BMI changes substantially with age, which makes setting BMI cut-off points for deciding overweight/obesity a bit difficult; and such BMI cut-off points will need adjustment for age to allow comparing the targeted children with their peers of the same age and sex (12).

On 2000, Cole et al. had provided age and genderspecific BMI cut-off points starting from childhood based on international data from different countries, which is linked to adults' cut-off points BMI $>25$ 
and $>30$ (age adjusted BMI based on International Obesity Task Force (IOTF) standards) (13).

Worldwide as well as in Japan, the recent reports have indicated that the prevalence of obesity in school children has been increasing rapidly in epidemic proportions (14). However, there are only few studies (15) on tracking of overweight/obesity in Japanese children ; and those studies are either including small sample sizes without using internationally acceptable definitions of childhood overweight/obesity or including a large sample size but of voluntary participants and without longitudinal tracking of obesity status that cannot guarantee generalization of their findings to all children in Japan (15-17). The purpose of our study is to demonstrate the temporal course of development of overweight/ obesity on a large scale among Japanese primary school children with tracking their BMI status into the junior high school adolescence period, in Tokushima prefecture, Japan.

\section{SUBJECTS AND METHODS}

\section{Subjects}

In the present study we aimed at studying the prevalence of overweight/obesity among school children at Tokushima Prefecture, Shikoku Island, Japan ; and to find out the age at which these Japanese children start to gain weight and develop overweight or obesity by tracking childhood overweight/ obesity of primary school children for six years. Our main target of such studies is to understand the starting age of the school children to become overweight or obese in order to tackle the problem at its early stages with the proper means of intervention.

For these purposes we designed a longitudinal prospective cohort study that started on April, 2001 ; with three cohorts of primary school children who belonged to $1^{\text {st }}$ grade i.e., 6 years old (Cohort A), $2^{\text {nd }}$ grade i.e., 7 years old (Cohort $\mathrm{B}$ ) and $3^{\text {rd }}$ grade i.e., 8 years old (Cohort $\mathrm{C}$ ) ; and followed up their height, weight and BMI annually, for six consecutive years till the year 2007. Data of the three baseline cohorts of 22,827 children $(11,824$ boys and 11,003 girls) were collected from all the 232 primary and 91 junior high schools in Tokushima Prefecture, Shikoku Island, Japan.

Throughout the six years cohort study, every year on the month of April, we assessed the anthropometric measurements (i.e., body weight and height) and calculate the BMI of every child in the three cohorts to detect the prevalence of overweight/ obesity among children and tracking their status as well as to calculate the percentages of children who returned to their normal BMI.

The anthropometric measurements (weight and height) were conducted for all the school children of the cohorts by the school nurses. Every child wore only the underclothing during the examinations. Weight was measured and recorded to the nearest $0.1 \mathrm{~kg}$, and height was measured and recorded to the nearest $0.1 \mathrm{~cm}$ using a manual height board. BMI was then computed for all the children using the formula, weight $(\mathrm{kg}) / \mathrm{height}\left(\mathrm{m}^{2}\right)$.

We encoded the collected data of all children according to their information regarding municipality, school, birth date and gender.

Since the data of children were kept anonymous for ethical considerations, we combined their anthropometric data during the six years cohort study with their age, sex, birth date, municipality and school code. While combining children's data, we found that many of them shared the same birth date, age, sex or school code, which complicated their data combination and caused them to remain unidentified. Thus, we omitted children who remained unidentified after data combination process or whose data were incomplete. The omitted data have not biased the analyzed children data. Additionally, we did not include data from schools for children with special needs. Therefore, our study was performed on data of 16,245 children $(8,427$ boys and 7,818 girls), whose data were complete and confirmed. Before starting this study we got the agreement of Tokushima board of education as well as the schools' administrations ; and the study was approved by the ethical committee of Tokushima University Hospital.

\section{Statistical methods}

After measuring the BMI for all children, they were classified as normal, overweight or obese by using BMI cut-off values according to the International Obesity Task Force by Cole et al. 2000 (13). At the baseline study and annually, the prevalence of overweight/obesity were determined. All analyses were done for boys and girls, separately. Statistical analyses were performed using the software of statistical package for social sciences, SPSS ver11 (SPSS Inc.). Boys and girls BMI, overweight, obesity and tracking status were compared by the chi square test. $P$ values less than 0.05 were considered significant. 
In this study "tracking of overweight" and "tracking of obesity" were defined as being overweight and obese from the baseline survey throughout the cohort till the final-year of the study. Among overweight/obese subjects at final year, the initial ages of onset of tracking overweight/obesity were identified. In each age category the number of subjects who first met the criteria of overweight/obesity during the follow-up was analyzed. We also analyzed the children BMI at the final-year of the research and compared it with the baseline data for tracking overweight/obesity of the three cohorts.

\section{RESULTS}

In this study, at the baseline study (on April, 2001) we measured the BMI for three cohorts of school children (cohort A, B and C) whose ages were 6,7 and 8 years, respectively. We followed up the overweight status of 16,245 children $(8,427$ boys and 7,818 girls) by measuring their body weight, height and BMI at 7 points of time ; at the baseline and once per year throughout the six years of this longitudinal cohort study.

Table 1 presents the annual means of $\mathrm{BMI} \pm \mathrm{SD}$

Table 1. Mean BMI values for Japanese boys and girls as measured in the baseline (2001) and the following annual cross-sectional studies (2002-2007) for cohorts A, B and C.

\begin{tabular}{|c|c|c|c|c|c|c|c|}
\hline & & & & Boys & $(\mathrm{n}=2743)$ & Girls & $(\mathrm{n}=2578)$ \\
\hline Cohort & Year & Grade & Age (y) & Mean & $\mathrm{SD}$ & Mean & $\mathrm{SD}$ \\
\hline \multirow[t]{8}{*}{ A } & 2001 & $1 \mathrm{st}$ & 6 & 16.13 & 2.11 & 15.89 & 2.00 \\
\hline & 2002 & 2nd & 7 & 16.44 & 2.34 & 16.15 & 2.17 \\
\hline & 2003 & $3 r d$ & 8 & 17.05 & 2.72 & 16.64 & 2.48 \\
\hline & 2004 & 4 th & 9 & 17.61 & 3.07 & 17.11 & 2.57 \\
\hline & 2005 & 5 th & 10 & 18.23 & 3.28 & 18.31 & 2.96 \\
\hline & 2006 & 6 th & 11 & 18.79 & 3.37 & 18.78 & 3.04 \\
\hline & 2007 & 7th & 12 & 19.55 & 3.57 & 19.25 & 3.12 \\
\hline & & & & & $(\mathrm{n}=2702)$ & & $(\mathrm{n}=2525)$ \\
\hline \multirow[t]{8}{*}{ B } & 2001 & 2nd & 7 & 16.50 & 2.38 & 16.26 & 2.17 \\
\hline & 2002 & $3 r d$ & 8 & 17.12 & 2.78 & 16.77 & 2.48 \\
\hline & 2003 & 4 th & 9 & 17.75 & 3.13 & 17.26 & 2.70 \\
\hline & 2004 & 5 th & 10 & 18.27 & 3.39 & 17.93 & 2.79 \\
\hline & 2005 & 6th & 11 & 18.86 & 3.45 & 18.60 & 3.04 \\
\hline & 2006 & 7th & 12 & 19.56 & 3.47 & 19.47 & 3.20 \\
\hline & 2007 & 8 th & 13 & 19.73 & 3.35 & 20.17 & 3.16 \\
\hline & & & & & $(\mathrm{n}=2982)$ & & $(\mathrm{n}=2715)$ \\
\hline \multirow[t]{7}{*}{$\mathrm{C}$} & 2001 & $3 r d$ & 8 & 17.01 & 2.68 & 16.79 & 2.46 \\
\hline & 2002 & 4 th & 9 & 17.68 & 3.01 & 17.31 & 2.78 \\
\hline & 2003 & 5 th & 10 & 18.25 & 3.26 & 17.86 & 2.95 \\
\hline & 2004 & 6 th & 11 & 18.71 & 3.33 & 18.68 & 2.94 \\
\hline & 2005 & 7th & 12 & 19.24 & 3.16 & 19.49 & 3.23 \\
\hline & 2006 & 8th & 13 & 19.97 & 3.53 & 20.19 & 3.11 \\
\hline & 2007 & 9th & 14 & 20.28 & 3.39 & 20.86 & 3.12 \\
\hline
\end{tabular}


for school boys and girls of cohorts A, B and C during the period from 2001 till 2007.

Table 2 shows the annual prevalence of overweight and obesity among Japanese boys and girls of three cohorts. Generally, the prevalence of overweight/obesity were significantly higher among boys compared to girls. At the baseline survey of cohort A, the percentage of overweight boys was about $15 \%$ and increased steeply, year by year till it reached its peak when the children were at the age of $10 \sim 11$ years old, i.e. while being in the $5^{\text {th }} \sim 6^{\text {th }}$ grades, primary schools. A similar overweight timetrend was observed for the other two boy cohorts of $\mathrm{B}$ and $\mathrm{C}$. However, the percentage of overweight girls reached its peak earlier than boys, as the highest percentage of overweight girls was noticed when they were at the age of $8 \sim 9$ years i.e., while being in their $3^{\text {rd }} \sim 4^{\text {th }}$ grade of primary school.

Tracking of overweight/obesity among school children was performed by comparing the BMI of children at the baseline with their status at the final year of the cohort study. Among boys, $10.43 \%$, $10.88 \%$ and $11.27 \%$ were tracked as overweight and $2.84 \%, 2.29 \%$ and $2.11 \%$ were tracked as obese boys for cohorts A, B and C, respectively. However, these percentages were lower for girls, where, $8.46 \%$, $8.23 \%$ and $8.55 \%$ were tracked as overweight and $1.32 \%, 1.27 \%$ and $1.29 \%$ were tracked as obese girls for cohorts A, B and C, respectively. Furthermore, $11.27 \%$ and $2.52 \%$ of boys' cohort $\mathrm{A}$, and $6.74 \%$ and $1.92 \%$ of boys' cohort B were found overweight and obese, respectively, at the final year of the study ;

Table 2. Prevalence of overweight and obesity among Japanese boys and girls of cohorts A, B and C, on each of the seven crosssectional studies between 2001 and 2007.

\begin{tabular}{|c|c|c|c|c|c|c|c|c|c|c|c|}
\hline \multirow[b]{3}{*}{ Cohort } & \multirow[b]{3}{*}{ Year } & \multirow[b]{3}{*}{ Grade } & \multirow[b]{3}{*}{ Age(y) } & \multicolumn{4}{|l|}{ Boys } & \multicolumn{4}{|l|}{ Girls } \\
\hline & & & & \multicolumn{2}{|c|}{ Overweight } & \multicolumn{2}{|l|}{ Obesity } & \multicolumn{2}{|c|}{ Overweight } & \multicolumn{2}{|l|}{ Obesity } \\
\hline & & & & Number & Percent & Number & Percent & Number & Percent & Number & Percent \\
\hline \multirow[t]{7}{*}{ A } & 2001 & $1 \mathrm{st}$ & 6 & 412 & 15.02 & 135 & 4.92 & 391 & 15.17 & 102 & 3.96 \\
\hline & 2002 & 2nd & 7 & 425 & 15.49 & 146 & 5.32 ** & 379 & 14.70 & 98 & 3.80 \\
\hline & 2003 & $3 r d$ & 8 & 536 & 19.54 * & 168 & $6.12^{\star *}$ & 439 & 17.03 & 87 & 3.37 \\
\hline & 2004 & 4 th & 9 & 564 & 20.56 ** & 170 & 6.20 ** & 429 & 16.64 & 69 & 2.68 \\
\hline & 2005 & 5 th & 10 & 583 & 21.25 ** & 164 & 5.98 ** & 403 & 15.63 & 62 & 2.40 \\
\hline & 2006 & 6 th & 11 & 572 & $20.85 * *$ & 151 & 5.50 ** & 394 & 15.28 & 46 & 1.78 \\
\hline & 2007 & 7 th & 12 & 595 & $21.69 * \star$ & 147 & 5.36 ** & 389 & 15.09 & 53 & 2.06 \\
\hline \multirow[t]{7}{*}{ B } & 2001 & 2nd & 7 & 466 & 17.25 & 154 & 5.70 * & 387 & 15.33 & 111 & 4.40 \\
\hline & 2002 & $3 r d$ & 8 & 545 & 20.17 ** & 186 & 6.88 ** & 433 & 17.15 & 110 & 4.36 \\
\hline & 2003 & 4 th & 9 & 598 & 22.13 ** & 190 & 7.03 ** & 437 & 17.31 & 85 & 3.37 \\
\hline & 2004 & 5 th & 10 & 625 & 23.13 ** & 164 & 6.07 ** & 426 & 16.87 & 71 & 2.81 \\
\hline & 2005 & 6 th & 11 & 631 & 23.35 ** & 147 & $5.44^{* *}$ & 423 & 16.75 & 64 & 2.53 \\
\hline & 2006 & 7th & 12 & 623 & 23.06 ** & 132 & 4.89 ** & 413 & 16.36 & 64 & 2.53 \\
\hline & 2007 & 8 th & 13 & 476 & 17.62 ** & 114 & $4.22^{* \star}$ & 372 & 14.73 & 51 & 2.02 \\
\hline \multirow[t]{7}{*}{$\mathrm{C}$} & 2001 & $3 r d$ & 8 & 545 & 18.28 & 177 & 5.94 ** & 464 & 17.09 & 112 & 4.13 \\
\hline & 2002 & 4th & 9 & 642 & $21.53 * *$ & 180 & 6.04 ** & 496 & 18.27 & 103 & 3.79 \\
\hline & 2003 & 5 th & 10 & 664 & 22.27 ** & 154 & 5.16 ** & 476 & 17.53 & 83 & 3.06 \\
\hline & 2004 & 6 th & 11 & 632 & 21.19 ** & 133 & 4.46 ** & 438 & 16.13 & 63 & 2.32 \\
\hline & 2005 & 7th & 12 & 561 & 18.81 & 107 & 3.59 & 467 & 17.20 & 75 & 2.76 \\
\hline & 2006 & 8 th & 13 & 530 & 17.77 * & 127 & 4.26 ** & 419 & 15.43 & 56 & 2.06 \\
\hline & 2007 & 9th & 14 & 491 & 16.47 & 108 & $3.62^{* *}$ & 420 & 15.47 & 60 & 2.21 \\
\hline
\end{tabular}

Chi square test was used for comparing boys' prevalence of overweight or obesity with that of the corresponding girls. 
however, at the baseline survey they were not. The percentages of children developing overweight/obesity were lower among girls' cohorts compared to their boys' peers (Table 3). To find out if there is any significant difference between boys and girls for becoming overweight or obese by the end of the six-year longitudinal study, we compared boys with girls within the non overweight-non overweight (NOW-NOW) and non overweight-overweight (NOW-OW) groups; and boys with girls within the non obese-non obese (NOB-NOB) and obeseobese (NOB-OB) groups.

Results show that boys in cohort A significantly became overweight $(\mathrm{p}<0.01)$ than girls ; and boys in cohorts $\mathrm{A}, \mathrm{B}$ and $\mathrm{C}$ had significantly become obese $(p<0.01, p<0.01$ and $p<0.05)$ than girls of the same cohorts.

Table 3 also shows comparison between boys and girls of groups overweight-overweight (OW-OW) and overweight-non overweight (OW-NOW) in cohorts $\mathrm{A}, \mathrm{B}$ and $\mathrm{C}$. The percentage of overweight girls who returned back to their normal BMI by the end of the cohort study $(6.7 \%, 7.1 \%$ and $8.6 \%$ for cohorts $\mathrm{A}, \mathrm{B}$ and $\mathrm{C}$, respectively) was significantly higher than boys $(4.5 \%, 6.4 \%$ and $7.0 \%$ for cohorts A, B and C, respectively). Similar trend was found for cohort $\mathrm{A}$, but not $\mathrm{B}$ or $\mathrm{C}$, when comparing boys and girls within the obese-obese (OB-OB) and obese-non obese (OB-NOB) groups.

Interestingly, for cohort $\mathrm{A}$, about $70 \%$ and $58 \%$ of

Table 3. Tracking of BMI, overweight and obesity status of Japanese school boys and girls from the baseline (2001) till the final year cross-sectional cohort study (2007).

\begin{tabular}{|c|c|c|c|c|c|c|}
\hline & Overweight tracking & & & Obesity tracking & & \\
\hline Cohort & Tracking status & Boys & Girls & Tracking status & Boys & Girls \\
\hline \multirow[t]{7}{*}{$\mathrm{A}$} & & $(\mathrm{n}=2743)$ & $(\mathrm{n}=2578)$ & & $(\mathrm{n}=2743)$ & $(\mathrm{n}=2578)$ \\
\hline & NOW-NOW (n(\%)) & $2022(86.7)$ & $2016(92.2)$ & NOB-NOB (n(\%)) & 2539 (97.4) & $2457(99.2)$ \\
\hline & NOW-OW (n(\%)) & $309(13.3) * *$ & $171(7.8)$ & NOB-OB (n(\%)) & $69(2.6)$ & $19(0.8)$ \\
\hline & Total & $2331(100.0)$ & $2187(100.0)$ & Total & $2608(100.0)$ & $2476(100.0)$ \\
\hline & OW-OW (n(\%)) & $286(69.4)$ & $218(55.8)$ & OB-OB (n(\%)) & $78(57.8)$ & $34(33.3)$ \\
\hline & OW-NOW (n(\%)) & $126(30.6) * *$ & $173(44.2)$ & OB-NOB (n(\%)) & $57(42.2)$ & $68(66.7)$ \\
\hline & Total & $412(100.0)$ & $391(100.0)$ & Total & $135(100.0)$ & $102(100.0)$ \\
\hline \multirow[t]{7}{*}{ B } & & $(\mathrm{n}=2702)$ & $(\mathrm{n}=2526)$ & & $(\mathrm{n}=2702)$ & $(\mathrm{n}=2526)$ \\
\hline & NOW-NOW (n(\%)) & $2054(91.9)$ & 1975 (92.3) & NOB-NOB (n(\%)) & $2496(98.0)$ & 2396 (99.2) \\
\hline & NOW-OW (n(\%)) & $182(8.1)$ & $164(7.7)$ & NOB-OB (n(\%)) & $52(2.0)$ & $19(0.8)$ \\
\hline & Total & $2236(100.0)$ & $2139(100.0)$ & Total & $2548(100.0)$ & $2396(100.0)$ \\
\hline & OW-OW (n(\%)) & $294(63.1)$ & $208(53.7)$ & OB-OB (n(\%)) & $62(40.3)$ & $32(22.8)$ \\
\hline & OW-NOW (n(\%)) & $172(36.9)$ ** & $179(46.3)$ & OB-NOB (n(\%)) & $92(59.7)$ & 79 (71.2) \\
\hline & Total & $466(100.0)$ & 387 (100.0) & Total & $154(100.0)$ & $111(100.0)$ \\
\hline \multirow[t]{7}{*}{$\mathrm{C}$} & & $(\mathrm{n}=2982)$ & $(\mathrm{n}=2715)$ & & $(\mathrm{n}=2982)$ & $(\mathrm{n}=2715)$ \\
\hline & NOW-NOW (n(\%)) & $2282(93.6)$ & $2081(92.4)$ & NOB-NOB (n(\%)) & 2760 (98.4) & $2578(99.0)$ \\
\hline & NOW-OW (n(\%)) & $155(6.4)$ & $170(7.6)$ & NOB-OB (n(\%)) & $45(1.6)$ & $25(1.0)$ \\
\hline & Total & $2437(100.0)$ & $2251(100.0)$ & Total & $2805(100.0)$ & $2603(100.0)$ \\
\hline & OW-OW (n(\%)) & $336(61.7)$ & $232(50.0)$ & OB-OB (n(\%)) & $63(35.6)$ & $35(68.8)$ \\
\hline & OW-NOW (n(\%)) & $209(38.3) * *$ & $232(50.0)$ & OB-NOB (n(\%)) & $114(64.4)$ & 77 (31.3) \\
\hline & Total & $545(100.0)$ & $464(100.0)$ & Total & $177(100.0)$ & $112(100.0)$ \\
\hline
\end{tabular}

NOW : non overweight $\mathrm{OW}$ : overweight

NOB : non obese OB : obese

Chi square test was used for comparing boys and girls regarding overweight or obesity tracking status.

${ }^{*} \mathrm{p}<0.05$

${ }^{* *} \mathrm{p}<0.01$ 
the baseline overweight and obese boys, compared to $56 \%$ and $33.3 \%$ of the baseline overweight and obese girls, respectively, were tracked with the same status of overweight or obesity by the end of the six years cohort study. The differences in the tracking percentages among overweight or obese boys and girls of cohort A were statistically significant, $p<0.01$. Similar trends were observed for the other overweight boys' cohorts of B and C, however, the significant level was met only when comparing the baseline overweight boys and girls.

Contrary to this, $44.3 \%, 42.3 \%$ and $50.0 \%$ of the initially overweight girls attuned their BMI to the normal standards by the end of the study compared to $30.6 \%, 36.9 \%$ and $38.4 \%$ of initially overweight boys, from cohorts A, B and C, respectively.

These findings indicate that Japanese boys are fatter and their overweight or obesity track into middle childhood and early adolescence than girls (Table 4).

\section{DISCUSSIONS}

Childhood overweight/obesity is increasing steeply, and growing globally in alarming trends (1-6). Furthermore, childhood overweight is a risk factor for severe obesity over the life course, with its-related morbidity and mortality from various diseases e.g., cardiovascular diseases, diabetes, cancers and metabolic syndrome (18-21).

Even though several overweight/obesity management programs are available for adults, most of these programs are not very successful (22). Therefore, detecting, predicting, treating and preventing overweight/obesity in childhood is worthwhile in programs aimed for combating adulthood obesity.

Studies designed for tracking overweight/obesity status from childhood into adulthood are of great help in this regard. Only few studies in Japan, have been designed to track childhood overweight status, and if present, it either includes a small number of

Table 4. Tracking childhood overweight and obesity among three cohorts of Japanese school boys and girls till the final-year of the six-year longitudinal study.

\begin{tabular}{|c|c|c|c|c|c|c|c|c|c|c|c|c|c|c|c|}
\hline \multirow[b]{3}{*}{ Cohort } & \multirow[b]{3}{*}{ Year } & \multirow[b]{3}{*}{ Grade } & \multirow[b]{3}{*}{ Age(y) } & \multicolumn{6}{|l|}{ Boys } & \multicolumn{6}{|l|}{ Girls } \\
\hline & & & & \multicolumn{3}{|l|}{ Overweight } & \multicolumn{3}{|l|}{ Obesity } & \multicolumn{3}{|l|}{ Overweight } & \multicolumn{3}{|l|}{ Obesity } \\
\hline & & & & N1 (\%) & $\mathrm{N} 2(\%)$ & Total & N1 & $\mathrm{N} 2$ & Total & N1 (\%) & $\mathrm{N} 2(\%)$ & Total & N1 (\%) & $\mathrm{N} 2(\%)$ & Total \\
\hline \multirow[t]{6}{*}{ A } & 2001 & $1 \mathrm{st}$ & 6 & $286(69.42)^{* *}$ & $126(30.58)$ & 412 & $78(57.78)$ ** & $57(42.22)$ & 135 & $218(55.75)$ & $173(44.25)$ & 391 & 34 (33.33) & 68 (66.67) & 102 \\
\hline & 2002 & 2nd & 7 & $299(70.35)$ ** & $126(29.65)$ & 425 & $85(58.22)$ ** & $61(41.78)$ & 146 & $227(59.89)$ & $152(40.11)$ & 379 & 35 (35.71) & 63 (64.29) & 98 \\
\hline & 2003 & $3 \mathrm{rd}$ & 8 & $377(70.34)^{\star *}$ & 159 (29.66) & 536 & $103(61.31)^{* *}$ & 65 (38.69) & 168 & 256 (58.31) & $183(41.69)$ & 439 & 37 (42.53) & $50(57.47)$ & 87 \\
\hline & 2004 & 4 th & 9 & $401(71.10)$ ** & $163(28.90)$ & 564 & 104 (61.18) & $66(38.82)$ & 170 & 270 (62.94) & $159(37.06)$ & 429 & 36 (52.17) & 33 (47.83) & 69 \\
\hline & 2005 & 5 th & 10 & $440(75.47)^{* *}$ & $143(24.53)$ & 583 & 107 (65.24) & 57 (34.76) & 164 & $271(67.25)$ & $132(32.75)$ & 403 & $36(58.06)$ & 26 (41.94) & 62 \\
\hline & 2006 & 6th & 11 & $463(80.94)$ ** & $109(19.06)$ & 572 & 108 (71.52) & $43(28.48)$ & 151 & $287(72.84)$ & $107(27.16)$ & 394 & $36(78.26)$ & 10 (21.74) & 46 \\
\hline \multirow[t]{6}{*}{ B } & 2001 & 2nd & 7 & $294(63.09)$ ** & $172(36.91)$ & 466 & $62(40.26)$ & $92(59.74)$ & 154 & $208(53.75)$ & $179(42.25)$ & 387 & 32 (28.83) & 79 (71.17) & 111 \\
\hline & 2002 & $3 \mathrm{rd}$ & 8 & $333(61.10)$ * & $212(38.90)$ & 545 & $70(37.63)$ & $116(62.37)$ & 186 & $233(53.81)$ & $200(46.19)$ & 433 & $32(29.09)$ & 78 (70.91) & 110 \\
\hline & 2003 & 4th & 9 & $363(60.70)$ * & 235 (39.30) & 598 & $75(39.47)$ & $115(60.53)$ & 190 & $236(54.00)$ & $201(46.00)$ & 437 & $34(40.00)$ & $51(60.00)$ & 85 \\
\hline & 2004 & 5 th & 10 & 386 (61.76) & 239 (38.24) & 625 & 77 (46.95) & 87 (53.05) & 164 & $256(60.09)$ & $170(39.91)$ & 426 & 33 (46.48) & 38 (53.52) & 71 \\
\hline & 2005 & 6th & 11 & 397 (62.92) & 234 (37.92) & 631 & 73 (49.66) & 74 (50.34) & 147 & 268 (63.36) & 155 (36.64) & 423 & 39 (60.94) & $25(39.06)$ & 64 \\
\hline & 2006 & 7th & 12 & $424(68.06)$ & 199 (31.94) & 623 & 88 (66.67) & 44 (33.33) & 132 & $301(72.88)$ & 112 (27.12) & 413 & $40(62.50)$ & $24(37.50)$ & 64 \\
\hline \multirow[t]{6}{*}{$\mathrm{C}$} & 2001 & $3 \mathrm{rd}$ & 8 & $336(61.65)$ ** & 209 (38.35) & 545 & $63(35.59)$ & 114 (64.41) & 177 & $232(50.00)$ & $232(50.00)$ & 464 & 35 (31.25) & 77 (68.75) & 112 \\
\hline & 2002 & 4th & 9 & 359 (55.92) & $283(44.08)$ & 642 & $71(39.44)$ & 109 (60.56) & 180 & 256 (51.61) & $240(48.39)$ & 496 & 33 (32.04) & $70(67.96)$ & 103 \\
\hline & 2003 & 5 th & 10 & 380 (57.23) & 284 (43.77) & 664 & $69(44.81)$ & 85 (55.19) & 154 & 267 (56.09) & 209 (43.91) & 476 & 31 (37.35) & 52 (62.65) & 83 \\
\hline & 2004 & 6th & 11 & $369(58.39)$ * & 263 (41.61) & 632 & $69(51.88)$ & 64 (48.12) & 133 & 287 (65.53) & $151(43.47)$ & 438 & 33 (52.38) & 30 (47.62) & 63 \\
\hline & 2005 & 7th & 12 & 399 (71.12) & $162(28.88)$ & 561 & $72(67.29)$ & 35 (32.71) & 107 & 314 (67.24) & $153(32.76)$ & 467 & $41(54.67)$ & 34 (45.33) & 75 \\
\hline & 2006 & 8th & 13 & $421(79.43)$ & 109 (20.57) & 530 & $88(69.29)$ & 39 (30.71) & 127 & $331(79.00)$ & $88(21.00)$ & 419 & $44(78.57)$ & $12(21.43)$ & 56 \\
\hline
\end{tabular}

$\mathrm{N} 1$ : Number of children tracked as overweight or obese between the concerned year and 2007.

$\mathrm{N} 2$ : Number of children started as overweight or obese at the concerned year but became non overweight or non obese by the end of the study at 2007.

Chi square test was used for comparing percentages of overweight or obese boys to that of corresponding girls.

${ }^{*} \mathrm{p}<0.05$

${ }^{* *} \mathrm{p}<0.01$ 
children or have not selected their children on a properly randomized basis $(15,16)$.

The current study was performed in Tokushima prefecture, Shikoku Island, which has one of the highest prevalence rates of obesity $(\mathrm{BMI}>25)$ among adults compared to the national figures of Japan. From national surveys, the prevalence of obesity was found to be $37.2 \%$ and $27.8 \%$ for males ; and $26.1 \%$ and $22.2 \%$, for females, as for Tokushima and nationwide values, respectively $(23,24)$. Further, a recent report on school health survey 2006, by the Japanese Ministry of Education, shows that the prevalence of overweight and severe obesity among Tokushima school children is higher than those of nationwide values (25).

Our study aimed at investigating the prevalence and tracking the status of overweight/obesity among three cohorts of school children, at Tokushima Prefecture, Shikoku Island, Japan. Therefore, we recruited all the primary schools in Tokushima (232 schools) to share in this longitudinal study. Hence, this cohort study included all the $1^{\text {st }} \sim 3^{\text {rd }}$ grades children of Tokushima Prefecture's primary schools ; and seven cross-sectional studies were performed from 2001 to 2007 to determine the weight, height and BMI of the children and track their BMI status from childhood into early adolescence.

Since several definitions for overweight/obesity currently exist, and due to the lack of reliable national Japanese definitions and cut-off points to be used as a national reference for determining childhood overweight/obesity, we have chosen IOTF cut-offs of Cole et al. 2000 (13), as a reference for this study.

Our results show that the prevalence of overweight is about $15 \sim 23 \%$ in boys and $15 \sim 18 \%$ in girls, however, for obesity the prevalence ranged between $4 \sim 7 \%$ in boys and $2 \sim 4 \%$ in girls. These results indicate that the prevalence of overweight/obesity is higher among Japanese boys than their age-peers' girls.

From the baseline study, about $15 \%$ and $5 \%$ of 6 years old boys were categorized as overweight or obese, respectively, just at the start of their primary school. A similar finding was observed for girls in cohort A, where $15 \%$ and $4 \%$ of girls have been already overweight or obese for age, respectively at the baseline survey.

These results indicate that overweight and obesity status start early in life; and for both sexes about $15 \%$ of children start as overweight and $~ 5 \%$ start as obese, even before the compulsory schools.
Furthermore, the highest percentages of obese boys were found when they were at the age of $8 \sim 9$ years old ( $3^{\text {rd }} \sim 4^{\text {th }}$ grade primary school), however, the girls' highest percentage of obesity was observed at the baseline study, and then it decreased in subsequent cross-sectional annual surveys.

These results show that overweight and obesity have been established in the early childhood periods even before the start of compulsory primary schools' life. Our findings are similar in this regard to that of Herman et al, 2008, who stated that a considerable number of overweight and obese adolescents were tracked from their preschool ages (26). Overweight/obesity that starts early in many children before the school age can be connected to the phenomenon of adiposity rebound and may track into mid-childhood and early adolescence. Williams and Goulding (2009) studied patterns of growth between ages 3 and 26 years and investigated its association with the timing of adiposity rebound. They concluded that early rebound is associated with increased depositions of fat in middle childhood, and risks associated with early rebound persist at least until early adulthood (27). Therefore, early preventive intervention programs for overweight/obesity are strongly recommended to start earlier during the preschool periods and continue through the school life.

Moreover, about $10 \sim 11 \%$ and $2 \sim 3 \%$ of our Japanese primary school boys tracked respectively, into overweight or obese junior high school adolescents. However, these percentages were lower among primary school girls where only $8.5 \%$ and $1.3 \%$ tracked into overweight and obese adolescent girls, respectively. These results indicate that the prevalence of overweight/obesity is higher among Japanese boys, whose childhood overweight/obesity is more tracked to early adolescence than the Japanese girls of the same age. These results regarding male and female differences for overweight/obesity prevalence can be explained by gender differences in body composition, lean body mass, energy intake and expenditure as well as gender differences in leptin synthesis and serum leptin concentration $(28,29)$.

As regards for tracking status, $\sim 70 \%$ of overweight $\sim 60 \%$ of obese Japanese primary school boys tracked into overweight or obese junior high school adolescents. However, these percentages are lower among primary school girls, where, only $\sim 55 \%$ overweight and $\sim 33 \%$ obese primary school girls tracked into overweight and obese adolescents, respectively. 
Those children continued to be overweight or obese throughout the six years study. Many epidemiological ; prospective and longitudinal studies have been performed worldwide, to study tracking of overweight/obesity from childhood into adulthood. Yet, there is no consensus about the tracking percentage of these studies that can be explained by the difference in target population sample size and characteristics, tracking period, age of starting tracking, follow up approaches as well as the definition of overweight/obesity and cut-off points used. Nonetheless, the majority of these studies consistently demonstrated the phenomenon of tracking and increased risk of overweight/obese children to become overweight adults (30-34).

Our results show a comparable tracking percentage to a prospective longitudinal study performed by Johannssonn $\mathrm{E}$ and his colleagues, where their persistence percentages of following up children aged 6, 7 and 8 years till the age of 9,12 and 15 years, were 72,62 and $51 \%$, respectively (35).

Interestingly, $30 \sim 40 \%$ of overweight primary school boys adjusted their BMI and became normal by the end of the study, but for girls the percentage was higher ; up to $50 \%$ of overweight girls attuned their normal BMI when being junior high school adolescents. Furthermore, $30 \sim 60 \%$ of obese boys and up to $70 \%$ of obese girls have reduced their BMI and changed their obese status to either normal or overweight by the end of the study

The frequency of obese girls may decrease during the junior high school periods due to the strong desire of high school girls to lose weight and become thinner during their early adolescence. Also, accelerated increase in stature can be a cause for the phenomenon of adjusted BMI during the junior high school period.

However, such desire of overweight adolescent girls should be governed by sound practice of weight reduction that should never come on the expense on their normal growth and body needs. Needless to say that health education must be considered as the key component for any intervention program that targets such children for controlling childhood overweight/obesity.

\section{CONCLUSIONS}

Japanese boys are fatter than girls and the prevalence of overweight/obesity is higher among boys than girls as determined in almost all our seven cross-sectional surveys performed from 2001 2007 . Generally, up to $70 \%$ of overweight/obese Japanese primary school children track into junior high school overweight/obese adolescents; and the tracking of overweight/obesity status is higher among boys than girls. Overweight and obesity status start early in life even at the preschool ages and track into early adolescence, therefore, programs intending to combat childhood overweight and obesity must start earlier during the preschool ages and to be continued throughout school life.

\section{REFERENCES}

1. Hill JO, Wyatt HR, Reed GW, Peter JC : Obesity and environment : where do we go from here? Science 299 : 853-5, 2003

2. Ebbeling CB, Pawlak DB, Ludwig DS : Childhood obesity : public-health crisis, common sense sure. Lancet $360: 473-82,2002$

3. Wang Y, Lobstein T: Worldwide trends in childhood overweight and obesity. Int J Pediatr Obes $1: 11-25,2006$

4. Kotani K, Nishida M, Yamashita S, Funahashi T, Fujioka S, Tokunaga K, Ishikawa K, Tarui S, Matsuzawa Y : Two decades of annual medical examinations in Japanese obese children : do obese children grow into obese adults? Int J Obes Relat Metab Disord 2 : 912-21, 1997

5. Matsushita Y, Yoshiike N, Kaneda F, Yoshita $\mathrm{K}$, Takimoto $\mathrm{H}$ : Trends in childhood obesity in Japan the last 25 years from the National Nutrition Survey. Obes Res 12 : 205-14, 2004

6. Ogden CL, Flegal KM, Carroll MD, Johnson CL: Prevalence and trends in overweight among US children and adolescents, 19992000. JAMA 288 : 1728-32, 2002

7. Csábi G, Török K, Jeges S, Molnár D : Presence of metabolic cardiovascular syndrome in obese children. Eur J Pedatr 159 : 91-4, 2000

8. Cook S, Weitzman M, Auinger P, Nquyen M, Dietz WH : Prevalence of a metabolic syndrome phenotype in adolescents : findings from the third National Health and Nutrition Examination Survey, 1988-1994. Arch Pediatr Adolesc Med $157:$ 821-7, 2003

9. Bacha F, Saad R, Gungor N, Janosky J, Arslanian SA : Obesity, regional fat distribution, and syndrome $\mathrm{X}$ in obese black versus white adolescents : race differential in diabetogenic and atherogenic risk factors. J Clin Endocrinol 
Metab 88 : 2534-40, 2003

10. Sei M, Nakatsu T, Yuasa K, Tanaka $H$, INDRIANI, Munakata H, Nakahori Y : Prevalence of metabolic complications in children with severe obesity. Pediatr Int $49: 545-52$, 2007

11. Laskarzewski P, Morrison JA, Mellies MJ, Kelly K, Gartside PS, Khoury P, Glueck CJ : Relationships of measurements of body mass to plasma lipoproteins in schoolchildren and adults. Am J Epidemiol 111 : 395-406, 1980

12. Rolland-Cachera MF, Sempé M, GuilloudBataille M, Patois E, Péquignot-Guggenbuhl F, Fautrad V : Adiposity indices in children. Am J Clin Nutr 36 : 178-84, 1982

13. Cole TJ, Bellizzi MC, Flegal KM, Dietz WH : Establishing a standard definition for child overweight and obesity worldwide : international survey. BMJ $320: 1240-3$, 2000

14. Yoshinaga $M$, Shimago A, Koriyama C, Nomura Y, Miyata K, Hashiguchi J, Arima K: Rapid increase in the prevalence of obesity in elementary school children. Int J Obes Relat Metab Disord 28 : 494-9, 2004

15. Sugimori H, Yoshida K, Miyakawa M, Izuno T, Takahashi E, Nanri S : Temporal course of the development of obesity in Japanese school children : A cohort study based on the Keio Study. J Pediatr 134 : 749-54, 1999

16. Inokuchi M, Hasegawa T, Anzo M, Matsuo N : Standardized centile curves of body mass index for Japanese children and adolescents based on the 1978-1981 national survey data. Ann Hum Biol 33 : 444-53, 2006

17. Funatogawa I, Funatogawa T, Yano E : Do overweight children necessarily make overweight adults? Repeated cross sectional annual nationwide survey of Japanese girls and women over nearly six decades. BMJ 337 : a802. doi : 10.1136/bmj.a802, 2008

18. Must A, Jacques PF, Dallal GE, Bajema CJ, Dietz WH:Long-term morbidity and mortality of overweight adolescents. A follow-up of the Harvard Growth Study of 1922 to 1935 . N Engl J Med 327 : 1350-5, 1992

19. Frontini MG, Bao W, Elkasabany A, Srinivasan SR, Berenson G : Comparison of weight-forheight indices as a measure of adiposity and cardiovascular risk from childhood to young adulthood : the Bogalusa heart study. J Clin Epidemiol $54: 817-22,2001$

20. Ferraro KF, Thorpe RJ Jr, Wilkinson JA : The life course of severe obesity : does childhood overweight matter? J Gerontol B Psychol Sci Soc Sci 58 : S110-9, 2003

21. Sorof JM, Turner J, Martin DS, Garcia K, Garami Z, Alexandrov AV, Wan F, Portman RJ : Cardiovascular risk factors and sequelae in hypertensive children identified by referral versus school-based screening. Hypertension 43 : 2148,2004

22. McManus K, Antinoro L, Sacks F : A randomized controlled trial of a moderate-fat, lowenergy diet compared with a low fat, low-energy diet for weight loss in overweight adults. Int J Obes Relat Metab Disord 25 : 1503-11, 2001

23. Ministry of Health, Labour and Welfare of Japan. Daiichi Publishing Co, Tokyo. The National Health and Nutrition Survey in Japan, 2003, 2006 (in Japanese)

24. Division of Health Promotion, Tokushima Prefectural Office, The Prefectural Health and Nutrition Survey in Tokushima, 2003, 2004 (in Japanese)

25. Ministry of Education, Culture, Sports, Science and Technology, National Printing Bureau, Tokyo, Report on School Health Survey 2006, 2007.

26. Herman KM, Craiq CL, Gauvin L, Katzmarzyk PT : Tracking of obesity and physical activity from childhood to adulthood: The Physical Activity Longitudinal Study. Int J Pediatr Obes $15: 1-8,2008$

27. Williams SM, Goulding A : Patterns of growth associated with the timing of adiposity rebound. Obesity $17: 335-341,2009$

28. Ellis KJ, Nicolson M : Leptin levels and body fatness in children : effects of gender, ethinicity and sexual development. Pediatr Res 42 : 484, 1997

29. Hassink SG, Sheslow DV, de Lancey E, Opentanova I, Considine RV, Caro JF : Serum leptin in children with obesity : relationship to gender and development. Pediatrics $98: 201-3$, 1996

30. Serdula MK, Collins ME, Williamson DF, Anda RF, Pamuk E, Byers TE : Weight control practices of U.S. adolescents and adults. Ann Intern Med 119: 667-71, 1993

31. Valdez R, Greenlund KJ, Wattigney WA, Bao $\mathrm{W}$, Berenson GS : Use of weight-for-height indices in children to predict adult overweight : the Bogalusa Heart Study. Int J Obes Relat 
Metab Disord 20 : 715-21, 1996

32. Power C, Lake JK, Cole TJ : Body mass index and height from childhood to adulthood in the 1958 British born cohort. Am J Clin Nutr 66 : 1094-101, 1997

33. Williams $\mathrm{S}$ : Overweight at age 21 : the association with body mass index in childhood and adolescence and parents' body mass index. A cohort study of New Zealanders born in 19721973. Int J Obes Relat Metab Disord 25 : 15863, 2001
34. Singh AS, Mulder C, Twisk JW, van Mechelen $\mathrm{W}$, Chinapaw MJ : Tracking of childhood overweight into adulthood : a systematic review of the literature. Obes Rev $9: 474-88,2008$

35. Johannsson E, Arngrimsson SA, Thorsdottir I, Sveinsson T: Tracking of overweight from early childhood to adolescence in cohorts born 1988 and 1994 : overweight in a high birth weight population. Int J Obes (Lond) $30: 1265-71$, 2006 